\title{
Characteristics of Cadets' Motor Abilities Development During Marksmanship Training
}

\author{
Kuznetsova Z.M. \\ University of management "TISBI" \\ Naberezhnye Chelny, Russia \\ kzm_diss@mail.ru
}

\author{
Chaban A.V. \\ Tyumen Higher Military-Engineering Command School \\ (military Institute) \\ Tyumen, Russia \\ chaban-zon-baron@mail.ru
}

\author{
Safina A.G. \\ University of management "TISBI" \\ Naberezhnye Chelny, Russia \\ kzm_diss@mail.ru
}

\begin{abstract}
The article presents the use of general, private and local means for cadets' motor abilities improvement during marksmanship training. One of the most important factors, which influences cadets' marksmanship training, is the speed of motor action fulfillment. It conditions mobilization of all complex of physiological systems of an organism and motor abilities. It is underlined that motor actions of a shooter are revealed during the following factors interaction: external and technical conditions of shooting fulfillment; motor abilities development; coordinating work of muscle and motor system of an organism. It should be noted that a shooter's motor actions are formed from interaction of the organism motor, vegetative and muscle systems.
\end{abstract}

Keywords-cadets; marksmanship training; motor abilities; motor actions.

\section{INTRODUCTION}

Marksmanship training is considered as one of the components of cadets' professionally-applied physical training at military higher educational establishments. The main characteristic of marksmanship training is static positions fulfillment for shooting from small arms. As the other kinds of training marksmanship training places high demands on cadets' organism. In these terms modern system of training demands connection of all elements and regularities of cadets' motor abilities development. Effective structure of marksmanship training helps to increase the effectiveness of the whole professionally-applied training system.

It is a well-known fact that motor actions during shooting from small arms are directed toward the main qualities of a shooter improvement: static position endurance, quickness of reaction, coordination of movement accuracy, muscle feelings, strength. During cadets' marksmanship training not only technical side of training is important, but also physical-functional training. All kinds of shooter's motor qualities are key components of general marksmanship training. Some specialists think that technical training is more important. Others consider motor training more important. Marksmanship training of cadets from military higher educational establishments is an important element of professionally-applied physical training since the $1^{\text {st }}$ course of study.

In order to reveal the importance of marksmanship training in professionally-applied physical training of cadets from military higher educational establishments literature review was realized. For example, Kalashnikov A.F. (2016) considers professionally-applied physical training of cadets as the condition for professionally-important qualities formation.

Slozhenikin A.P. (2015) underlines the necessity to estimate the degree of marksmanship training level influence on psycho-physiological state of military department members.

Frolova I.V. (2014) writes, that the training process management among athletes-shooters is impossible without modern technical teaching means use.

Kuznetsova Z.M., Chernova N.A. (2011) consider the importance of conditions for students' personal qualities program realization in educational activity. It is one of the real preconditions for the specialist training renewal content in the system of higher education. The authors also give characteristics to this approach importance for all specialties. Khvastunova E.M. (2015) studies modern technical means use in marksmanship training. 
I.Y. Syuzev (2015), A.I. Zhuzhgov (2015), Z. Kuznetsova, A. Kuznetsov, I. Mutaeva, G. Khalikov, A. Zakharova, (2015), S.P. Khozei, (2017) underline the necessity of innovations in teaching and consider the problems of their introduction into educational process of cadets' marksmanship training and the necessity to form professionally important qualities among military higher educational establishment cadets by means of physical training.

In order to achieve this aim it is necessary to create practical and methodical conditions with necessary means and material-technical support of lessons.

Sadiev N.N. (2015) underlines, that for successful future profession mastering by cadets it is necessary to take into consideration and use modern achievements of military practice [147, p. 19].

A.V. Chaban, Z.M. Kuznetsova, A.V. Ryabchuk (2017) think that psychological training is necessary for individual and mutual actions of cadets and that is why it is important to develop independency, consistency, inclination to risk and the ability to interact in a team.

A. Kuznetsov, I. Mutaeva, Z. Kuznetsova, (2017) consider functional training diagnostics as the main component of sports training effectiveness in different kinds of sport.

The aim of the research is to create the methodology of cadets' motor abilities development during marksmanship training from small-arms.

\section{RESEARCH METHODOLOGY}

The research was held on the basis of Federal State Budgetary Educational Establishment of Higher Education "Tyumen Higher Military-Engineering Command School (military Institute)" in Tyumen. With the help of pedagogical observation structural components of motor action and cadets' motor abilities during shooting from small-arms was studied.

\section{RESULTS}

Characteristic feature of shooting from small-arms is in the fact that in terms of tense conditions it is necessary to realize shooting precisely. Structural components of a shooter's motor activity are closely connected with each other (the initial position, ready position, aiming and a shot), which a shooter has to fulfill clearly, precisely and quickly. It depends on a shooter's technical mastery and on the level of motor abilities demonstration.

It is noted that considerable tension of a shooter's activity is conditioned by several psychic characteristics of cadets' marksmanship training.

One of the most important factors, which influence cadets' marksmanship training, is the speed of motor action fulfillment. It conditions mobilization of the whole complex of physiological systems of an organism.
A shooter's motor actions are revealed during the following factors interaction: external and technical conditions of shooting; physical qualities development; coordinating work of muscle and motor systems of the organism. It should be noted that a shooter's motor actions are formed from motor, vegetative and muscle systems interaction.

In order to improve cadets' motor abilities during marksmanship training it is necessary to define total volume of a shooter's technical-tactical actions. Mean values of a total volume (effective and not effective) of cadets' technical-tactical actions during shooting are widely varied and depend on the conditions of shooting (lying, standing, on a knee, with a moving object, daily and night shooting, plane shooting).

The indices of activity and effectiveness of cadets' shooting motor actions vary. It is proved by the results of shooting actions in case of successful and not successful attempts.

We studied the indices of cadets' individual actions during successful and not successful attempts of shooting. In case of successful attempts cadets had precise target hitting in terms of variability till $5 \%$. In case of not successful attempts variability of motor actions was till $23 \%$.

For cadets' marksmanship training development it is necessary to select special exercises, directed toward psychological steadiness, functional readiness, accuracy, balance and dexterity development. It is important to train holding the projectile. It influences effectiveness indices of a shot. Bringing weapon to the target is trained in special conditions after complete rest for static power endurance development.

Fig. 1 presents the ratio of exercises structural components within one lesson.

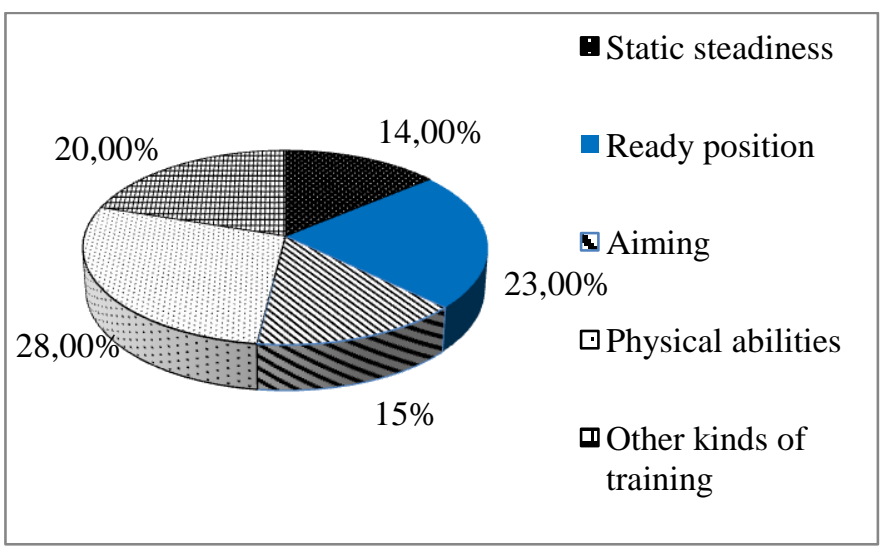

Fig. 1. The ratio of exercises directed toward cadets' marksmanship training improvement within one lesson

Picture 1 shows that the percentage of the defined structural components of a shooter's motor activity varies from stage to stage of training. In particular, the most important exercise is static steadiness development. It takes $14 \%$ of the 
whole time within one lesson. Ready position takes $23 \%$ of the whole time for getting ready for shooting. Aiming at the initial stages of marksmanship training takes $45 \%$ from the whole time volume.

We come to the conclusion that the structural components of a shooter's motor actions during marksmanship training depends on a structural transformation of motor actions and the abilities during professional mastery improvement.

\section{IV.CONCLUSION}

Thus, at the initial stages of cadets' marksmanship training prevail the actions, directed toward small arms mastering. It takes $50 \%$ of the whole time volume (ready position $43,00 \%$; aiming- 23,00\%). Specific weight of aiming increase happens in terms of shooting the moving target.

It can be noted that from course to course the time that cadets spend on the separate shooting components changes and it proves marksmanship mastery improvement. The peculiarity of the training programs, directed towards cadets' motor abilities improvement, is the necessity to take into account: individual characteristics of shooting actions formation; the initial level of physical and functional readiness; the level of accuracy, balance, dexterity demonstration; an individual tempo of movement; psychological stability

\section{References}

[1] Zhuzhgov A. I. The level of physical load at cadets' military-applied physical training lessons at military higher educational establishments. Pedagogicopshycological and medico-biological problems of physical culture and sport. 2015, vol. 1(34), pp. 42-46. URL: http://www.vak.webtm.ru/index.php/arkhivnomerov?id $=384$

[2] Kalashnikov A. F. Professionally important qualities formation among cadets by means of professionallyapplied physical training. The collection of articles “Actual problems of cadets', listeners' and students' physical culture and sport". Moscow, 2016, pp. 53-57.

[3] Kuznetsova Z. M., Chernova N.A. The program realization of students' personal qualities formation in educational activity as one of real preconditions for training content renewal in the system of higher education (by the example of students from PovSAPCSaT in "Service and tourism" specialty). Pedagogico-pshycological and medico-biological problems of physical culture and sport. 2011, vol. 1(18), pp. 143-149. URL: http://www.journalscience.org/ru/article/378.html.

[4] Sadiev N. N. Technology of cadets' military-applied physical readiness development at military-engineering higher educational establishment. Physical culture, sport - science and practice. 2015, vol. 1, pp. 19-25.

[5] Slozhenikin A. P. The degree of marksmanship training level influence on psycho-physiological state of military department members. Modern problems of humanitarian and natural sciences: materials of the XXVI International scientific-practical conference. Moscow. 2015, pp. 187-194.

[6] Syuzev I. Yu. Innovations in teaching and the problems of their introduction into educational process concerning marksmanship training. Training workers for military departments: modern directions and educational technologies: materials of the XX AllRussian scientific-practical conference. Irkutsk. 2015, pp. 163-167.

[7] Tolubaeva Yu.A. About psychological bareer among cadets at marksmanship training lessons. Training for law enforcement agencies: modern trends and educational technologies: materials of the XVII AllRussian scientific-methodical conference. Irkutsk. 2012, pp. 304-307.

[8] Khvastunova E. M. Modern technical means, used in marksmanship training. Russian Federation interior ministry Barnaul institute bulletin. 2015, vol. 1(285), pp. 65-66.

[9] Khozei S. P., Solonitsyn D.A., Salnikov V.A. Innovative part in professionally important qualities formation among cadets of military higher educational establishments by means of physical training. Physical culture in the system of professional education: ideas, promising technologies: materials of the II All-Russian scientific-practical conference. Omsk, 2017, pp. 112127.

[10] Chaban A. V., Kuznetsova Z.M., Ryabchuk A.V. Marksmanship training of military higher educational establishment cadets on the basis of psychic processes development. Pedagogico-pshycological and medicobiological problems of physical culture and sport. 2017, vol. 12(2), 146-153. DOI: 10.14526/01_2017_216

[11] Kuznetsova Z., Kuznetsov A., Mutaeva I., Khalikov G., Zakharova A. Athletes preparation based on a complex assessment of functional state. In Proceedings of the $3^{\text {rd }}$ International Congress on Sport Sciences Research and Technology support. SCITEPRESS. 2015, pp. 156-160.

[12] Kuznetsov A., Mutaeva I., Kuznetsova Z. Diagnostics of Functional State and Reserve Capacity of young Athletes' Organism. In Proceedings of the $5^{\text {th }}$ International Congress on Sport Sciences Research and Technology support. SCITEPRESS. 2017, pp. 111115. 